\title{
Indagaciones sobre Semiótica Jurídica
}

\author{
Oscar Quezada M.
}

\section{PUNTOS DE PARTIDA}

Como señala Kalinowski (K: 1985), la semiótica jurídica permanece como un proyecto por realizar. Son los sucesivos trabajos de este autor los que permiten afirmar que, en su constitución, la semiótica jurfdica hereda la esquizia Peirce/Saussure que caracteriza a la semiótica general. Efectivamente, Kalinowski se inscribe, a través del modelo de Ch.W. Morris, en la tradición "peirciana" del pragmatismo americano apuntalado por el positivismo lógico de R. Carnap y R. Montague. Omite explícitamente las semióticas concebidas de otro modo tales como las de Ch. Bonarzis, A.J. Greimas, H. Hermes y J. Kristeva. Radical, señala que sólo a partir de los tres autores citados inicialmente se estará "en condiciones de indicar lo que podria, e incluso lo que debería ser la semiótica jurídica" (K: 1985).

Por el otro lado, el primer precedente sistemático que aproxima la teoria semiótica de tradición "saussureana" al campo del derecho parece ser, contemporáneamente, el estudio que A.J. Greimas en colaboración estrecha con E. Landowski, efectúa en 1970 a solicitud del Centro de Investigación sobre el derecho de los asuntos de la Cámara de Comercio e Industria de París. Dicha investigación titulada: Análisis Semiótico de un discurso juridico. La ley comercial sobre las sociedades y los grupos de sociedades (G.L.: 1976) es el hito inicial que impulsa luego sucesivas aproximaciones al campo del derecho patrocinadas y desarrolladas sobre todo por E. Landowski y R. Carrión. 
No es de mi interés detallar aquí esta sucesión de trabajos. Incluso dentro de la tradición francesa seguidora de las tesis de G. Mounin tenemos los trabajos de André-Jean Arnaud (A.J.A.: 1978-1985) traducidos al castellano, uno de análisis estructural del Código Civil francés y el otro de aproximación a la jurisprudencia del divorcio a través de las sentencias de los jueces en la Corte de Apelación de Aix-en-Provence entre 1968. 1971. Se configura así un complejo universo de aproximaciones semióticas al dominio de lo jurídico que, repito, no reseñaré a fondo, pues no es esa la intención de esta indagación. Baste con reconocer las grandes tradiciones de pensamiento que desde diversas pertinencias epistemológicas han ido perfilando el objeto jurídico.

Es asi que, desde Peirce, Morris y Kalinowski desembocamos más en una lógica del derecho, articulada en base a la tripartición sintáctica/ semántica/pragmática. Dicha lógica se muestra exhaustiva en la creación de sistemas (a priori) y en la descripción de sistemas (a posteriori) esbozando de esta manera una semiótica pura y una semiótica empírica; referidas, ambas, más a los sistemas que a los procesos. De esta manera, el esfuerzo teórico de estos autores se orienta hacia una semiótica sistemática del lenguaje del derecho. Ahora bien, "hay tantos lenguajes del derecho como legislaciones actualmente o históricamente vigentes. Por otra parte, cada uno de ellos está constituido, en la mayoría de los casos, a partir de otro lenguaje natural (el griego, el latín, el chino, el ruso, etc.). aunque pueda suceder que un mismo lenguaje natural sirva de fuente para la enunciación de varias legislaciones, o dicho de otro modo, para la enunciación de varios lenguajes del derecho".

Si nos preguntamos ¿cómo se construye lo juridico en tanto que objeto semiótico? veremos que ambas tradiciones parten del reconocimiento del lenguaje natural. Greinas y Landowski en ASDJ presentan tres presupuestos básicos en la expresión discurso jurídico. EI primero: intertextual en relación de inclusión. Dicho discurso se manifiesta en un subconjunto de textos al interior de los textos manifestados en una lengua natural, p.ej., el castellano. Este primer presupuesto aunque pueda parecer evidente es muy importante tanto para Kalinowski como para Greimas. Ambos lo toman en cuenta, uno para iniciar la elaboración de sintácticas particulares relativas a un determinado lenguaje, el otro para constituir metodológicamente su objeto. Volvamos a los presupuestos greimasianos.

El scgundo: sintagmático lineal. Entender semióticamente lo juridico es aprehenderlo en su encadenamiento frástico (lexemas, sintagmas, enunciados) y transfrástico (parágrafos, capítulos, o, en fin, "discursos"
circunstanciales). 
El tercero pramatical. La calificación /jurídico/ conlleva una organización especifica de unidades constituyentes (sintáctico) y una connotación particular subtendida por este género de discursos (semántico).

Desde Saussure, Greimas y Landowski el resultado es, pues, una gramática discursiva del derecho. Nos sentimos, por ello, más cerca de los procesos. El segundo presupuesto es elocuente. A la función lógica del signo jurídico se va contraponiendo su función social. Las dos grandes vertientes terminan por construir objetos disímiles (puede que epistemológicamente complementarios, no es el caso discutirlo): una teoría queda anclada en las funciones de las expresiones lingūisticas en tanto expresiones adaptadas a un segundo lenguaje cuyo objetivo es enunciar una legislación. La otra teoría se preocupa no tanto de la lógica de los signos constitutivos del lenguaje sino de la gramítica de las relaciones, operaciones y vertimientos constitutivos del discurso.

\section{GRAMATICA, DISCURSO Y TEXTO EN LO JURIDICO}

Sin desestimar los aportes de la vertiente "peirciana", me orientarế, por razones de (de)formación teórico-metodológica, hacia una reflexión de dominante estructural-generativista, es decir, greimasiana. Bastará extrapolar los aportes más recientes aparecidos en los Diecionarios (G.G.: 1979-1986) con el trabajo inicial sen̂alado líneas arriba, para extraer de este ir y venir las sugestiones hipotéticas generales así como las posibles "refracciones" aplicativas a virtuales corpus de nuestro entorno histórico.

Analizando aquellos tres criterios previos que, en tanto ordenadores metodológicos sobredeterminan la construcción del objeto, me doy cuenta de que el primero se localiza en el plano de la manifestación material de lo juridico y los otros dos en el plano lógicamente anterior del recorrido generativo de su producción.

Efectivamente, si recordamos la teoría elaborada en estos años, ta tesis del recorrido generativo de la significación se desarrolla desde las estructuras más abstractas o paradigmáticas (semionarrativas) propias del presupuesto gramatical señalado en ASDJ hacia las estructuras concretas o discursivas propias del presupuesto sintagmático, lineal.

La totalidad de ese recorrido generativo se manifiesta en y con una lengua natural a través de unas propuestas perceptivas materiales denominadas textos (entre otros textos de dicha lengua natural: primer presupuesto). 
He aquí una extrapolación que, en sintesis, se pucde formular como tres modos de existencla semiótica de lo juridico, Modo de existencia real: texto jurídico. Modo de existencia actual: discurso juridico. Modo de existencia virtual: gramática juridica.

Pues bien. continuando con los alcances de esta remisión al recorrido generativo de to jurídico entendemos que hay, cntre la gramática y el discurso, presupuestos lógicanente por cada texto, una instancia de la enunciación jurídica, Lugar de producción del discurso (producto) bien sea desde la posición de enunciación enunciadora (Destinador o Emisor del discurso jurídico) o desde la posición de enunciación enunciataria (Destinatario o Receptor del discurso juridico).

En efecto, todo discurso se jucga entre un cnunciador y un enunciatario. El sujeto de la enunciación es doble, la problemática de la comunicación de lo juridico es sólo comprensible a partir de sus condiciones significativas en tanto competencias de sujetos productores. En este marco lo juridico es una co-producciom. No se trata de un simple receptor al modo mecanicista y vacfo de muchas "teorias de la comunicación". Nuestro destinatario es un co-productor de sentido, inscrito en el texto como signo. En el discurso el yo, al constituir al tủ como signo. se construye también como tal.

Podemos afirmar, entonces, que la semiótica del derecho es elaborada por un sujeto para otro al interior de una lengua natural ( $y$ con una lengua natural). Respecto al vehículo expresivo, el Derecho no puede no ser verbal. Podríamos concebir semióticas adyacentes que expresen circunstancialmente aspectos de algo que primordial y originalmente es pensado y concebido verbalmente. Cada lenguaje reclama su semiótica. Es en razón del dualismo existente en el campo del derecho que tenemos, por un lado, et lenguaje del derecho (lenguaje en el cual son enunciadas las reglas juridicas) $y$, por el otro, el lenguaje de los juristas (lenguaje en el cual estos últimos hablan del primero). Dirá Kalinowski (1985) que la semiótica juridica. en sentido amplio, es la suma de las semióticas respectivas de uno y otro lenguaje. En realidad, esta distinción entre el lenguaje del derecho y el lenguaje de los juristas es un caso particular de la distinción entre el lenguaje-objeto y el metalenguaje. En sentido estricto es la semiótica del lenguaje del derccho la que constituye la semiótica jurídica.

Retomando lo central del planteamiento de Greimas/Landowski. diremos con ellos que "el discurso jurídico no es más que un caso particu- 
lar. definible en su especificidad, entre todos los discursos posibles -y realizados- en una lengua natural cualquiera. A partir de las propiedades generales de los discursos - y de lo que se sabe de ellos- se pueden deducir algunas características generales o especificas del discurso juridico".

En base a todo esto, podemos entender que el discurso juridico tiene su sujeto. Que éste es una instancia construida: efecto de sentido del enunciado-discurso. Construido por aquél. Este sujeto es, pues, un actante sintáctico que manipula las categorías lingûísticas que constituyen su competencia global y las categorías jurídicas que constituyen su competencia especifica y las hace pasar de su organización sistemática virtual a su puesta en escena discursiva, al encadenamiento sintagmático realizado como programa discursivo. Si desmenuzamos la competencia de este sujeto habrá que discernir niveles de lengua: con la lengua natural él construye una lengua del derecho. Me refiero en concreto a todo un complejo metalenguaje vinculado a una multiplicidad casuística (civil, penal, administrativo, procesal, laboral, etc.) que opera como referente.

Así, en la mediación enunciativa no sólo se da una actualización de la lengua sino que también sc toman en cuenta especificas categorías semánticas necesarias para que el sujeto opere, manipule y organice los términos de su discurso por los procedimientos de la predicación. En este sujeto se halla dispuesto el conjunto de mecanismos y procedimientos de la puesta en discurso de la lengua: la gramática del Derecho, en tanto simulacro lógico y temático-narrativo, estará depositada en el sujeto como una paradigmática, como un nivel especial de lengua (de ahi el derecho como régimen de especialistas: juristas).

Es este nivel especial de lengua el que constituye la competencia del sujeto de la enunciación (o digamos también de la comunicación) de lo juridico. Concebida polarmente bien sea para formular el texto, es decir, competencia legislationa, o para interpretarlo y aplicarlo: competencia hermenéutica y, ulteriormente, judicial. En fin, esta problemática especifica conducirá directamente a las sobredeterminaciones cconómico-politicas de lo juridico, es decir, al marco peneral en el que su sujeto se manifiesta.

\section{DIMINSIONES DE LA NARRATIVIDAD JURIDICA}

Por to dicho anteriormente, en el seno de cualquier formación social hay una formación ideológica sostenida por una lengua natural. Con materiales de esta última es posible no solamente "hablar del mundo y de 
los hombres" sino también formular discursos especificos dotados de una cierta autonomía. Una doble problemática queda asi esbozada: el sujeto de la lengua natural constituye significaciones particulares -como las del discurso jurídico- es decir, da cuenta de un espacio referencial relativamente distanciado produciendo un discurso de segundo grado $y$, simultáneamente, se remite a las significaciones que dependen de diferentes y diversos metadiscursos dando cuenta, esta vez, de un espacio referencial en el que convergen, entremezclándose en una polisememia, todos los ins. tantes de la cotidianeidad. Asi, en el discurso cotidiano de un peruano que es abogado o profesor de Derecho se realiza una mezcla muy compleja de elementos pertenecientes a los discursos jurídico, económico. político y cultural, en general.

Todo esto da pie a otra extrapolación. La teoría semiótica distingue, en principio, dos dimensiones narrativas del relato: la dimensión cognoscitiva, relativa a las diversas formas de articulación del saber (comunicación, producción, manipulación, organización, descripción, recepción... según un saber); y la dimensión pragmática, relativa al aspecto figurativo - concreto semánticamente - de las cosas, objetos, hechos y/o eventos del mundo natural, es decir, a los comportamientos somáticos significantes. El referente interno de lo cognoscitivo es, asi, siempre, lo pragmatico (G-C, : 1979).

Pues bien, muchos años antes, en ASDJ, los autores hablan del discurso jurídico diciendo que aparece "manchado" por una especie de duplicidad, es decir que se desarrolla sobre una doble isotopia: la primera está representada por el discurso legislativo, hecho de enunciados performativos y normativos, instaurando seres y cosas, instituyendo las reglas de los comportamientos lícitos e ilícitos: la segunda aparece bajo la forma de un discurso referencial que, no siendo más que una elaboración ideológica, una cubierta discursiva del mundo, se da como el mundo social mismo, anterior a la palabra que lo articula.

No es mi intención aparear las dos dimensiones con las dos isotopias puesto que sólo en la isotopia legislativa parecen hallarse componentes pragmáticos y cognoscitivos, pero sí dar clara cuenta de cómo la isotopía legislativa está más cerca a la dimensión cognoscitiva e incluso incorpora un fuerte componente tímico al axiologizar las conductas lícitas e ilícitas connotando euforicamente a las primeras y disfóricamente a las segundas. Son estas conductas, referentes permanentes de lo legislativo, las que constituyen su isotopia referencial obviamente más próxima a la dimensión pragmática. Así, el discurso legislativo reenvía constantemente a las signifi- 
caciones del discurso referencial, como sí éste fuera no sólo isótopo sino también isomorfo con "la realidad del mundo" anterior al discurso legislativo, que no sería más que palabra sobre las cosas cuya existencia es evidente. Sin embango, esta presuposición lógica es del orden del parecer semiotico.

En el orden del ser semiótico es el discurso legislativo ei que, seleccionando los elementos referenciales en la lengua natural respectiva, les confiere el estatuto de nivel referencial $y$. operando su clausura en relación a las significaciones circundantes, las integra en el discurso juridico. Por lo tanto, desde una optica inmanente el nivel legislativo es anterior y se halla lógicamente presupuesto por el nivel referencial. Es el nivel legislativo el que constituye su propio nivel referencial al interior del discurso jur ídico.

Los comportamientos están ya desde siempre legislados. Si la sintaxis es la legislación de la lengua, lo jurídico es la legislación de esa legislación. Por este orden del orden se dan las clasificaciones que permiten separar a los buenos sujetos de los malos sujetos y fundar la convivencia social. St el lenguaje ordena lo real la legislación ordena, de nuevo, este orden. Son los intereses del sujeto legislador los que, en última instancia, sobredeterminan la utopia juridico-política que su discurso reproduce. El sentimiento de "realidad" de la isotopía referencial, pragmática, del discurso, se impone al destinatario como un verosimil social, como la evidencia que organiza la palabra legislativa. Esta es recibida, así, como to "natural".

\section{CONSTITUCION MODAL DE LA LEGISLATIVIDAD}

Siendo una forma particular de la certeza, esta evidencia que es el verosimil social no exige que el destinatario de la ley ejerza hacer interpretativo alguno. Ya el otro lo ha hecho por es. El destinatario acepta el mundo tal cual la ley lo inagina. Asi. por ejemplo, en nuestra constitución es verosímil el abandono del nifio, del adolescente y del anciano. Tan 2s asi que el agente del abandono no se especifica (ver Art. 8 de la Constitución). Fista posibilidad (poder-ser) del abandono está construida en el enunciado, F!I creer cnunciativo del enunciatario actúa hipotácticamente sobre esta posibilidad y queda así articulada la modalización epistémica conpleja de to remosimil: creer que puede-ser así. Vemos como la ley hace aceptar una realidad en tanto referente.

De alguna manera, en la dimensión pragmática del discurso jurídico, quedan suprimidas las distancias entre el discurso referencial y el discurso 
cognoscitivo-legislativo. Este sanciona a aquèl. Asi, siguiendo con nuestro ejemplo, los actores objeto del abandono "son protegidos por el Estado". Este ahora del imperativo legal nos lleva a la necesidad (deber-ser). Sobre esta necesidad actúa el creer enunciativo enunciatario y la resultante es la modalización epistémica compleja de la certidumbre: creer que debe-ser asi. Además de una realidad, la ley hace aceptar un orden que la rige.

Dos niveles del creer se articulan en la constitución de la legislatividad sobremodalizando al ser de ta posibilidad y de la necesidad y dando por resultado, respectivamente, un verosimil y una certiclumbre. Siendo ésta una modalidad episténica primaria y aquélla una modalidad epistémica secundaria, caracterizamos la conexión entre estas modalidades como una rección: la certidumbre rige a lo verosímil. Esta rección se manifiesta en el carácter performativo de la norma jurídica.

En otros términos, a un posible problema se hace corresponder una necesaria solución. En el caso que venimos presentando el agente de dicha solución es el Estado. Este actante queda, asi, comprometido con una acción que, en tanto proceso, pucde ser expresada: protección. Se sobreentiende que dicho actante es competente respecto al hacer en cusstión. Este efecto de competencia corrobora la convertibilidad del ser y del hacer: el correlato de la modalización epistémica de lo jurídico es su modalización ética. Obviamente, esta conversión nos lleva a perfilar los límites politicos de lo juridico. Asi. es fácil para el enunciatario ver comprometido al Estado con la protección a los nimos, adolescentes y ancianos. Esta protección está prescrita. La prescripción (deber-hacer) es objeto de un creer enunciativo que la modaliza dando por resultado el compromiso: crecr que eso se debe-hacer.

Esta modalidad ética primaria tiene status de indiscutible. No suce. de lo mismo con la modalidad ética secundaria, pues a pesar de estar semióticamente construida en el texto es cvaluada prąmáticamente por el intertexto de lo social. Tenemos así trazados los límites políticos de los que hablabamos. Hasta que punto coincide la libertad (poder-hacer) del Estado con su capacidad. Siendo esta libertad objeto de un creer enunciativo tenemos el efecto de competencia. El enunciatario está en condiciones de creer que eso se puede-hacer.

Pero el enunciatario está sometido al texto de la historia-relato. Es actor y narrador de su experiencia. Puede poner en tela de juicio la capacidad del Estado para cumplir con la ley que él mismo se da. De hecho, en nuestro país, muchas máximas constitucionales como ésta son utopias 
netas. LI Fistado aparece comprometido con tuna competencia a la que no accede. La ley es, politicamente, referente de una tensión de incompeten(ia (G.C.: 1986).

Todas estas determinaciones se manifiestan discursivamente gracias a las modalidades veridictorias que permiten construir, a partir de las distinciones del ser y del parecer, niveles de realidad. El enunciatario no sólo desarrolla un ereer epistémico (creer que puede ser como es porque así debe ser) y ético (creer que el Estado puede o no puede hacer lo que debe hacer); ademais, la legislatividad to mantiene en la tensión de construir un referente "real", "verdadero".

\section{ASPECTOS DE LA COMPETENCIA JURIDICA}

Lo Icgislativo y su referencia aparecen trenzados, fundidos en el texto juridico. Fundandolo. Son, de esta manera, las únicas "realidades" que se presentan al análisis semántico: sus dependencias, interdependencias, interreferencias e interferencias modelan una problemática estructural generativa que da cuenta de la especificidad del discurso juridico como tal.

El derecho positivo o el discurso juridico aparecen como sistemas secundarios que no solamente son sostenidos por las lenguas naturales, en tanto sistemas semióticos primarios, sino que se relacionan, a través de ellas, con los sistemas semióticos "naturales", es decir, no-lingüísticos: la vida social misma como relato en el que se manifiestan estructuras económicas, sociales, sexuales. afectivas; vale decir: cotidianas.

El sistema semiótico primario que es la lengua natural tiene, obviamente, sus sistemas de reglas gramaticales. Lo mismo sucede con este sistema semiótico secundario: todo discurso jurídico es producido, en cuanto a su forma, por una gramática juridlica distinta de la (o las) gramática(s) de la(s) lengua(s) natural(es) en la (o en las) que este discurso se manifiesta. Istos dos tipos de gramática son otros tantos niveles de competencia del sujeto de la enunciación jurídica.

Todo un universo semántico juridico se manifiesta bajo la forma lexical (palabras, expresiones, etc.) en una especie de diccionario jurídico autónomo. Si cl discurso jurídico remite a una gramática, entonces lo hace también a un diceionario y puede. por lo tanto, afirmarse que dicho discurso es la manifestación de un lenguaje, de una semiótica jurídica depositada en el sujeto como saber. 
Este era aproximadamente el razonamiento de Grcimas y Landowski en ASDJ y constituía su hipótesis inicial: el texto que describieron era concebido como dependiendo en su articulación de una seuniótica juridica producto de una gramática y manifestación de un universo semántico particular (que definen la competencia del especialista). Dicha gramática. contrariamente a cualquier tipo de semióticas sociales cuya gramática está implicita, se quicre explicita y fija ostensiblemente el cucrpo de sus reglas (dándole académicamente carácter de doctrina). Lo ideal es evacuar toda ambigüedad. Presentarse como gramática bien hecha. Más que una serie deductiva de reglas estamos ante un cuasi-manual que toma la forma de un inventario no muy ordenado de definiciones y prescripciones entrete. jidas referencialmente.

La gramática juridica es una gramática explicitamente construida y se anuncia como tal. Se puede decir que se trata de un discurso gramatical (código en sentido jurídico) producido por un código jurídico (códiso en sentido semiótico) que está ausente, implicito en cl discurso mismo. en sus condiciones de producción. Otra de las tareas semióticas es justamente la reconstrución formal del sistema juridico subyacente a los numerosos discursos. Esto sólo se puede hacer a partir del análisis de las competencias de los sujetos construidos en dichos discursos.

En el Dicfiomaire // (1986) Roqué Carrión, a propósito de lat entrada Juridique (Sémiorique), presenta una definición en sentido amplio y otra en sentido restringido. Em aubas subsisten los componentes teóricos de la concepeión inicial de Greimas y Landowski que venimos reseñando.

Dice Carrión, refiriéndose al sentido amplio, que "se puede entender por semiótica juridica todo sistema de reglas que regulan las relaciones entre actantes desde el punto de vista de stis derechos. Dentro de esta perspectiva, la semiótica jurídica no es más que un campo particular de las sintaxis modales de tipo potestativo y deóntíco siendo éstas a su vez analizables sea en el cuadro gencral de la teoría semio-narrativa, sea en términos puramente lógicos (cf, Kalinowski)".

He subrayado el aspecto sistemático referido a las reglas para destacar el carícter gramatical de la concepción semio-narrativa de lo jurídico. Por otro lado, el desarrollo al interior de la semiótica cstructural de la teoría de las modalidades es tal que, luego de estos afos, la semiótica jurídica se define como un campo más de aplicación de las sintaxis potes. fativas y deónticas elaboradas por la teoría semio-narrativa. Cabe anotar la referencia a Kalinowski para entender que dichas sintaxis pueden ser 
vistas lógicamente como conjuntos de reglas constitutivas o fundamentales.

El reconocimiento teórico del papel de las modalínades se ve de nuevo reflejado en el Diccionario // cuando Landowski explica como, en el campo de lo que denominamos Derecho. se encuentra manifestada parcialmente toda una sintaxis de derechos $y$ deberes que no es sino el sistema regulador de las relaciones entre los actantes al que se refiere $\mathrm{Ca}$ rrión: dice Landowski (1986): "Desde el punto de vista semiótico, la noción de derecho remite a una problemática modal que se puede situar en la articulación de lo 'potestativo' (tener el derecho de .... es poder-hacer; tener derecho a... es poder-ser) y de lo deóntico (obtener eso a lo que tengo derecho compromete un deber-hacer de parte del otro; el respeto de mis derechos implica un deber no-hacer de parte del otro, etc.). La sintaxis de los derechos y de los deberes que se diseña de esta manera, se encuentra parcialmente formulada en el marco del derecho positivo o discurso jurídico en sentido estricto".

Queda entendido que la formulación de las diversas sintaxis modales de los derechos y de los deberes se sigue planteando en el marco de investigaciones concretas y que junto a la categoria clasemática de lo /comercial/ que caracterizó a la primera aproximación semionarrativa se han ido investigando las peculiaridades de otros vertimientos semánticos: to /civil/. to /penal/, lo /administrativo/. to /procesal/, to /laboral/, to /tributario/, lo /constitucional/, etc.

Del mismo modo, el rol de lo "potestativo" y lo deóntico se dejó entrever en la disquisición relativa a la constitución modal de la legislatividad. Cabe una reflexión práctica de nuestro pequefio corpus constitucional. Respecto a lo propuesto por Landowski, tenemos una sintaxis potestativa que regula las relaciones entre "la madre" y "el Estado". El primero de estos actantes es objeto de una modalización potestativa del poder-ser: tiene derecho a la protección del Estado y a su asistencia en caso de desamparo (Art. 7). Al Estado le compete, pues, la existencia misma de "la madre". Fisto significa que, deónticamente, a este derecho de protección y amparo, corresponde un deber-hacer del Estado que deviene sujeto comprometido, virtual destinador.

Igualmente, si leemos que: "TI Estado garantiza a los padres de familia el derecho de intervenir en el proceso educativo de sus hijos..." (Art. 23), estaremos ante una potestatividad más dinámica y funcional referida a un sujeto de hacer: los padres. Por último, si digo que: "EI 
derecho $a$ la educación y cultura es inherente a la persona humana..." (Art. 21) entenderé que el respeto de este derecho implica que el Estado debe no-abandonar la promoción educativa y cultural.

Todo esto da una idea de cómo se va esbozando senióticamente la problemática modal en el dominio del Derecho.

\section{UN SISTEMA DE PRODUCCION Y VERIFICACION}

Es pertinente notar como subyace bajo todo este jucgo modal la oposición entre los enunciados del ser y del hacer. Bien sea que estén, epistémica o éticamente, sobremodalizados por el creer. O que permitan inscribir la dimensión potestativa correspondiente a la modalización del poder o la deóntica relativa a las posiciones basadas en deber-hacer.

Ahora es pertinente observar el rol de esta oposición en la categorización del sistema jurídico. Dicen Greimas y Landowski en ASDJ que las categorías propias del lenguaje jurídico permiten discriminar un orden del ser y un orden del hacer.

En el orden del ser, que en la teoría clásica define a los enunciados calificativos, el enunciado equivale al dicho del decir (dit du dire) del legislador. Es lo existente. Sólo lo explicitamente dicho posee el estatuto de existente. Correlativamente, lo no-dicho es lo no-existente (tema de la nulidad jurídica). Lo que no es sociedad legal no es, no existe. Nombrar y definir los objetos es esencial en la práctica juridica. Esta práctica supone dos dimensiones: la producción del derecho y la verificación de la conformidad entre los enunciados sobre el mundo y los enunciados canónicos del lenguaje jurídico. En el orden del ser, la oposición dicho vs. nodicho funda la gramática jurídica en tanto construcción arbitraria y explicita.

En el orden del hacer se trata de fijar, en base a to que la teoría define como enunciados funcionales, la esfera operacional del objeto semiótico ya llamado a la existencia. El conjunto de comportamientos previsibles se halla sometido a la apreciación de un enrejado modal. Teóricamente, el inventario de comportamientos que el legislador trata de reglamentar surge del nivel referencial más o menos explícito e intenta abarcar la totalidad del universo justiciable considerando jurídicamente existentes sólo los comportamientos prescritos (deber-hacer) o si no como inexistentes los comportamientos prohibidos (deber no-hacer). Lo más frecuente es ver en los sistemas jurídicos un sincretismo de los dos tipos de reglas. 
Tanto en su origen - como palabra performativa absoluta que instaura un orden del mundo convencional y explícito- como en su organización Ilamando, por el hecho de que los enuncia, a los seres a la existencia $y$ atribuyéndoles funciones precisas, delimitadas por reglas prescriptivis y prohibitivas - el sistema jurídico parece ser una estructura sólida e immóvil (se habla así de la "inmutabilidad" del derecho). Pero este es sólo el orden del parecer. Esta aparente inmutabilidad no impide que el sistema evolucione, se complete y se transforme gracias a los discursos juridicos que hacen repercutir sus innovaciones. Toda esta sintesis de lo planteado nor Greimas y Landowski apunta a la comprensión de cómo la gramática juridica se retroalimenta con la príctica jurídica. Esta última es producción del derecho, de reglas y de significaciones jurídicas nuevas y, al mismo tiempo, un procedimiento recumente de verificación de la validez del lenguaje juridico constituido. La fuerza del lenguaje juridico estầ en el hecho de que practica constantemente procedimientos de verificación. Ello es posible gracias a la estructura particular de delegación del poder: el destinador original de los mensajes jurídjeos -es decir, el legisladores sustituido por un destinador suplente - delegado- llantado a re-decir el derecho y que se llana justicia.

La jurispnadencia se presenta como un espectáculo: las partes y cl tribunal actúan a la manera de dramatis personae caracterizadas. Los procedimientos a los que nos referiamos líneas arriba corresponden a la manifestación de las unidades narrativas del lenguaje juridico. Los microrelatos del discurso jurídico -artículo tras artífulo, fallo tras fallo-son descripciones de programas, de comportamientos organizados según relaciones lógicas, narrativas y temporales cuyo desarrollo está instituido como "conveniente". No se trata tanto de descripciones de comportamientos sino de desarrollos

tos sino de desarrollos ejemplares de procedimientos. De modelos del hacer juridico que, al ser descritos, pasan a tener una existencia juridica. Estos modelos, al someterse a la modalización prescriptiva o prohibitiva constituyen moldes, "formas" en el sentido jurídico de la palabra, en los que se realizan los vertimientos de los comportamientos no-juridicos del nivel referencial, para comprobar su conformidad. La práctica juridica es, pues. una hermencutica permancute.

Volviendo a la cuestión del espectáculo diremos, por ejemplo, que en la constitución de una sociedad, sea conyugal, comercial o política; los procedimientos que describen su instalación, corresponden a la secuencia narrativa del establecimiento del contrat to y de la instauración de unos sujetos dotados de un querer performador. Lo mismo sucede con las moda- 
lidades del poder y del saber que caracterizan a tales agentes o a tales órganos o instituciones sociales y, especificamente en lo comercial, los procedimientos de verificación de las cuentas que pueden ser formalmente interpretados como la "glorificación del héroe" o la "revelación del traidor" del cuento folklórico.

Sucede entonces como si la sociedad, desde su nacimiento hasta su muerte, pasara una serie de etapas-pruebas, conformándose a las reglas de comportamiento que son simultáneamente antropomorfizadas y juridicamente ejemplares. De esta manera. los procedimientos juridicos, aun obedeciendo a las reglas de la gramática jurídica en sentido estricto, dependen al mismo tiempo de la gramática semionarrativa. De ahi el rol de la semió. tica en la formulación de una metodologia apropiada para estudiar el conjunto de procedimientos juridicos, Reconocer las propiedades semionarrativas del discurso jurídico es aceptar que se pueden y deben utilizar los modelos semionarrativos generales para dar cuenta de la organización de dicho discurso. La teoria semionarrativa general servirá para examinar las relaciones particulares de la semionarratividad con el discurso juridico.

\section{BALANCE (APARENTEMENTE) FINAL}

Falta explorar otros enunciados modales que articulan el derecho de las personas. Queda también "en el tintero" la posibilidad de hacer una lectura semiótica del acto juridico como acto productor de sentido. En fin, el horizonte es immenso. Por ello, restringiendo el sentido en pro de una "piedra de toque", Carrión señala que "la semiótica juridica tiene la tarea de dar cuenta del discurso del derecto (positivo) y. en la medida de sus posibilidades, de asignarle su lugar en el marco de una tipología de los discursos" (G.C.: 1986).

En este esfuerzo se inscribe la presente indagación, rudimentaria aún, pero que ha querido ser un informe, un "mapa nocturno" de los vectores disciplinarios centrales y gravitantes para la comprensión semiótica del texto jurídico. 


\section{CLAVES BIBLIOGRAFICAS}

(K: 1985) Kalinowski, Georges: La Semiótica Jurídica. Para una teoría de las funciones de las expresiones lingüisticas. Versión castellana en: Cuadernos de Semiótica Jurí. dica. CELIJS. Facultad de Derecho de la Universidad de Carabobo, Valencia, Venezuela. 1985.

(G.L.: 1976) : Greimas, A.J, y Landowski, E. Análisis Semiótico de un discurso jurídico. La ley comercial sobre las sociedades y los grupos de sociedades. En: Sémiotique et sciences sociales. Editions du Seuil, Paris 1976. Para los efectos del presente trabajo me refiero a la presente investigación con las siglas ASDJ.

(A.J.A.: 1978) : André Jean Arnaud: Ensayo de analisis estructural del Código Civil francés. La regla del juego en la paz burguesa. Universidad de Zulia. Facultad de Derecho. Instituto de Filosofía del Derecho. Maracaibo. Ve. nezuela. 1978 .

(A.J.A.: 1985) : Arnaud, André-Jean: Un efemplo de Estudio Semiológico de la Jurisprudencia. El divorcio en Aix-en-Provence, Versión castellana. En: Cuadernos de Semiótica Jurídica. CELIJS. Facultad de Derecho de la Universidad de Carabobo. Valencia. Venezuela. 1985.

(G.C.: 1979) : Greimas, A.J, y Courtés, J.: Sémiotique, Dictionnaîre raisonné de la Théorie du Langage. Libraire Hachette. Paris. 1979.

(G.C.: 1986) ; Greimas, A.J. y Courtés, J.: Sémiotique. Dictionnaire raisonné de la Théorie du Langage. (Compléments, débats, propositions). Libraire Hachette. Paris. 1986. 